GASTRIC CANCER

\title{
Two distinct aetiologies of cardia cancer; evidence from premorbid serological markers of gastric atrophy and Helicobacter pylori status
}

\author{
Svein Hansen, Stein Emil Vollset, Mohammad H Derakhshan, Valerie Fyfe, Kjetil K Melby, Steinar \\ Aase, Egil Jellum, Kenneth E L McColl
}

Gut 2007;56:918-925. doi: 10.1136/gut.2006.114504

See end of article for authors' affiliations

\section{Correspondence to:} Professor K E L McColl, Division of Medical Sciences, Western Infirmary, University of Glasgow Glasgow G1 1 6NT, Ú; k.e.I.mccoll@clinmed.gla. ac.uk

Revised 12 January 2007 Accepted 17 January 2007 Published Online First 22 February 2007

\begin{abstract}
Background: Non-cardia gastric adenocarcinoma is positively associated with Helicobacter pylori infection and atrophic gastritis. The role of $H$ pylori infection and atrophic gastritis in cardia cancer is unclear. Aim: To compare cardia versus non-cardia cancer with respect to the premorbid state of the stomach. Methods: Nested case-control study. To each of 129 non-cardia and 44 cardia cancers, three controls were matched. Serum collected a median of 11.9 years before the diagnosis of cancer was tested for anti-H pylori antibodies, pepsinogen I:II and gastrin.

Results: Non-cardia cancer was positively associated with $H$ pylori (OR $4.75,95 \% \mathrm{Cl} 2.56$ to 8.81 ) and gastric atrophy (pepsinogen I:II <2.5; OR 4.47, 95\% Cl 2.71 to 7.37). The diffuse and intestinal histological subtypes of non-cardia cancer were of similar proportions and both showed a positive association with $H$ pylori and atrophy. Cardia cancer was negatively associated with $H$ pylori (OR $0.27,95 \% \mathrm{Cl} 0.12$ to 0.59 ), but $H$ pylori-positive cardia cancer showed an association with gastric atrophy (OR $3.33,95 \% \mathrm{Cl} 1.06$ to 10.5). The predominant histological subtype of cardia cancer was intestinal and was not associated with gastric atrophy compared with the diffuse subtype ((OR $0.72,95 \% \mathrm{Cl} 0.19$ to 2.79 ) vs (OR $3.46,95 \% \mathrm{Cl} 0.32$ to 37.5)). Cardia cancer in patients with atrophy had an intestinal: diffuse ratio (1:1) similar to non-cardia cancer (1.9:1), whereas cardia cancers in patients without atrophy were predominantly intestinal (7:1).

Conclusion: These findings indicate two aetiologies of cardia cancer, one associated with $\mathrm{H}$ pylori atrophic gastritis, resembling non-cardia cancer, and the other associated with non-atrophic gastric mucosa, resembling oesophageal adenocarcinoma. Serological markers of gastric atrophy may provide the key to determining gastric versus oesophageal origin of cardia cancer.
\end{abstract}

$\mathrm{S}$ everal observations indicate that cancers of the cardia region of the stomach are aetiologically different from those of the rest of the stomach. Cancers of the mid and distal stomach (non-cardia cancers) show a strong positive association with Helicobacter pylori infection, whereas cardia cancer has negative, positive or no association with $H$ pylori infection. ${ }^{1}$ The incidence time trends of cardia and non-cardia cancer also differ, with the latter falling and the former remaining static or increasing. . $^{2-5}$

Substantial advances have been made in our understanding of the aetiology of non-cardia cancer and, in particular, of the role of $\mathrm{H}$ pylori infection. The highest risk of non-cardia cancer is in patients in whom the infection has induced atrophic gastritis and low or absent acid secretion. ${ }^{6}$ Non-cardia cancer is the result of progression from $H$ pylori superficial gastritis to atrophic gastritis and hypochlorhydria to dysplasia and finally to cancer.?

The aetiology of cancer of the gastric cardia region remains poorly understood. One reason for this may be the anatomical complexity of the cardia. Cardia mucosa extends from the oxyntic mucosa of the body of the stomach to the squamous mucosa of the distal oesophagus. The mucosa consists of columnar mucosa resembling that of the gastric antrum. In neonates, the cardia mucosa is only a few millimetres in length. ${ }^{8}$ In adults, the cardia mucosa may be larger, and this expansion may occur by metaplasia of the adjacent mucosa into cardia-like mucosa. ${ }^{9-12}$ Proximal extension of cardia mucosa can occur by metaplastic transformation of the squamous mucosa of the distal oesophagus-a phenomenon that may be induced by acidic gastro-oesophageal reflux. Distal extension of cardia mucosa may arise from atrophic gastritis of oxyntic mucosa with loss of specialised cells and most commonly induced by $H$ pylori infection. ${ }^{913}$ When patients present with adenocarcinoma involving the gastric cardia, it is usually impossible to determine whether the tumour has arisen from metaplasia of the distal oesophageal squamous epithelium, from metaplasia of gastric oxyntic mucosa or from the original cardia mucosa.

In a large nested case-control study in the Norwegian population, we found that $H$ pylori infection was associated with an increased risk of non-cardia cancer but with a reduced risk of cardia cancer. ${ }^{14}$ The current study was undertaken to compare cancers at those two sites with respect to premorbid gastric mucosal atrophy and acid secretion.

The aim of this study was to examine the association between the state of the gastric mucosa and the risk of subsequently developing cardia versus non-cardia gastric cancer.

\section{PATIENTS AND METHODS}

This was a nested case-control study. It comprised 101601 men and women enrolled in the Norwegian Janus ${ }^{15}$ cohort as blood donors in Oslo 1973-86, as participants in the Oslo Study of Cardiovascular Disease $1972-73^{16}$ and as participants in the Norwegian Counties Study 1974-78 carried out by the National Health Screening Service in the three counties Oppland, Sogn og Fjordane and Finnmark. ${ }^{16}{ }^{17}$ All solid gastric cancers diagnosed among the cohort members through 1992 were

Abbreviation: PGI:II, pepsinogen I to pepsinogen II ratio 
Table 1 Risk of gastric adenocarcinoma for Helicobacter pylori serostatus, quintiles of serum pepsinogen I:Il and quintiles of serum gastrin concentration according to different gastric subsites and adenocarcinoma subtypes

\begin{tabular}{|c|c|c|c|c|c|}
\hline Risk factor & $\begin{array}{l}\text { Cardia ( } 44 \text { cases, } \\
132 \text { controls) }\end{array}$ & $\begin{array}{l}\text { Non-cardia overall (129 } \\
\text { cases, } 376 \text { controls)* }\end{array}$ & $\begin{array}{l}\text { Non-cardia, intestinal } \\
\text { ( } 59 \text { cases, } 173 \text { controls) }\end{array}$ & $\begin{array}{l}\text { Non-cardia, diffuse ( } 35 \\
\text { cases, } 100 \text { controls) }\end{array}$ & $\begin{array}{l}\text { Non-cardia, mixed ( } 31 \\
\text { cases, } 91 \text { controls) }\end{array}$ \\
\hline \multicolumn{6}{|l|}{ H pylori serostatus } \\
\hline Negative & 1.00 (reference) & 1.00 (reference) & 1.00 (reference) & 1.00 (reference) & 1.00 (reference) \\
\hline Positive & $0.27(0.12$ to 0.59$)$ & 4.75 ( 2.56 to 8.81$)$ & 3.96 (1.69 to 9.27$)$ & 3.90 (1.11 to 13.7$)$ & 5.51 (1.52 to 20.0$)$ \\
\hline $\mathrm{p}$ Value & 0.001 & $<0.005$ & 0.002 & 0.034 & 0.010 \\
\hline \multicolumn{6}{|l|}{$\begin{array}{l}\text { Serum pepsinogen I:Il } \\
\text { quintiles }\end{array}$} \\
\hline 5th $6.060-30.973$ & 1.00 (reference) & 1.00 (reference) & 1.00 (reference) & 1.00 (reference) & 1.00 (reference) \\
\hline 4th $4.803-6.055$ & $0.24(0.07$ to 0.75$)$ & 1.21 (0.48 to 3.05$)$ & $1.07(0.30$ to 3.74$)$ & 0.31 (0.03 to 3.33 ) & 4.35 (0.44 to 43.4$)$ \\
\hline $3 r d 3.777-4.795$ & $0.68(0.27$ to 1.74$)$ & 2.49 (1.07 to 5.78$)$ & $1.50(0.47$ to 4.82$)$ & $2.02(0.46$ to 8.86$)$ & $13.4(1.20$ to 150$)$ \\
\hline 2nd 2.691-3.774 & $0.14(0.03$ to 0.71$)$ & 5.35 (2.35 to 12.2$)$ & 2.96 (0.94 to 9.29$)$ & $7.82(1.87$ to 32.6$)$ & $14.6(1.35$ to 157$)$ \\
\hline lst $0.323-2.688$ & $0.78(0.26$ to 2.39$)$ & $11.6(4.91$ to 27.5$)$ & 12.5 (3.57 to 43.9$)$ & 6.29 (1.45 to 27.3$)$ & 24.9 (2.28 to 272$)$ \\
\hline $\mathrm{p}$ Value for trend & 0.391 & $<0.005$ & $<0.005$ & $<0.005$ & 0.002 \\
\hline \multicolumn{6}{|c|}{ Serum gastrin quintiles ( $\mathrm{ng} / \mathrm{l}$ ) } \\
\hline lst $2-20$ & 1.0 (reference) & 1.0 (reference) & 1.0 (reference) & 1.0 (reference) & 1.0 (reference) \\
\hline 2nd $25-30$ & $1.25(0.44$ to 3.55$)$ & $1.99(0.82$ to 4.83$)$ & $1.56(0.44$ to 5.52$)$ & $8.19(0.80$ to 84.2$)$ & $1.75(0.30$ to 10.2$)$ \\
\hline $3 r d 35-55$ & $1.58(0.58$ to 4.28$)$ & $2.45(1.13$ to 5.35$)$ & $1.82(0.59$ to 5.58$)$ & $10.6(1.13$ to 99.0$)$ & $1.66(0.37$ to 7.41$)$ \\
\hline 4th $60-90$ & $0.71(0.19$ to 2.66$)$ & $3.82(1.77$ to 8.23$)$ & $3.66(1.23$ to 10.9$)$ & $8.42(0.97$ to 73.2$)$ & $3.44(0.82$ to 14.5$)$ \\
\hline 5th $95-462$ & $1.63(0.48$ to 5.48$)$ & 8.99 (3.96 to 20.4 ) & $12.8(3.83$ to 42.6$)$ & $21.8(2.29$ to 208$)$ & $3.68(0.77$ to 17.7$)$ \\
\hline $\mathrm{p}$ Value for trend & 0.702 & $<0.005$ & $<0.005$ & 0.007 & 0.042 \\
\hline
\end{tabular}

Values are represented as OR $(95 \% \mathrm{Cl})$.

*Including four histologically unclassifiable cases and 12 corresponding controls.

identified in The Cancer Registry of Norway. Cases were limited to individuals with available historical serum from whom primary tumour tissue could be verified as gastric adenocarcinoma of unequivocal non-cardia or cardia origin. Of the 230 identified gastric cancer cases, 57 were excluded from the study because of no remaining or wasted serum $(n=7)$, no tissue $(\mathrm{n}=2)$ or only metastatic tumour tissue $(\mathrm{n}=10)$ available for histological examination, histological type diagnosed or suspected to be other than adenocarcinoma $(n=6)$, doubt about the stomach being the primary site of the tumour $(n=2)$, gastric resection before the diagnosis of cancer $(n=16)$, or disseminated tumour growth precluding determination of cardia/non-cardia subsite origin $(\mathrm{n}=14)$. To each cancer case, controls were matched according to gender, date of birth (within 54 months, 97\% within 12 months, median deviation 3 months), date of serum sampling (within 17 months, 99\% within 12 months, median deviation 3 months) and serum source (blood donors, the Oslo Study of Cardiovascular Disease, or county within Norwegian Counties Study). In all, three controls were matched to 162 cases, and two controls were matched to 11 cases.

The gastric adenocarcinoma cases were classified according to subsite as tumours of the cardia, fundus, body, antrum or pylorus in accordance with the International classificaton of diseases for oncology, second edition ${ }^{19}$ after review of all clinical, biopsy and resection reports submitted to the cancer registry. When needed, endoscopy and radiology reports were consulted. Cardia cancers were defined as tumours whose centre was judged to be within $2 \mathrm{~cm}$ distal to the gastro-oesophageal junction. Adenocarcinomas largely or entirely located within the distal oesophagus were excluded. All diagnoses of adenocarcinoma were verified on new pathology slides of biopsy or resection specimens and classified according to subtype, as given by Laurén, ${ }^{20}$ as intestinal, diffuse or other. The "other" subgroup closely corresponds to "mixed" in newer terminology. ${ }^{21}$ Five cases were subtype-unclassifiable because of insufficient size of the biopsy specimen.

Serum was collected from each cohort member at the start of follow-up and thereafter kept frozen at $-25^{\circ} \mathrm{C}$. The time lapse between the last meal and serum sampling was categorised as $<1$, l-2, 2-4, 4-8 and $>8 \mathrm{~h}$. Serum anti-H pylori IgG concentration (average of two readings) was measured using the Pyloriset EIA-G Test Kit (Orion Diagnostica, Espoo, Finland). For detection of current or previous $H$ pylori infection (ever infection), we chose a cut-off of $250 \mathrm{U} / \mathrm{l}$, which is lower than the cut-off of $500 \mathrm{U} / \mathrm{l}$ recommended by the manufacturer for detection of current infection..$^{14}$ The results of the $H$ pylori serology have been published previously. ${ }^{14}$ Serum gastrin concentration was measured using antibody R98, which detects both gastrin 17 and gastrin $34 .^{22}$ Serum pepsinogen I and pepsinogen II concentrations were measured using radioimmunoassay kits (Sorin Biomedica Diagnostics, Saluggia, Italy).

We validated the ability of serum pepsinogen I to pepsinogen II ratio (PGI:II) to detect atrophy. This was performed using stored serum from 175 H pylori-positive patients with non-ulcer dyspepsia who had undergone endoscopy with antral and body biopsies. Atrophy of body and antrum was graded as absent, mild, moderate or severe according to the updated Sydney classification of gastritis. ${ }^{23}$ Low PGI:II was valuable in detecting atrophy involving the gastric body. At a cut-off point of 2.5, the sensitivity and specificity of PGI:II were $71 \%$ and $67 \%$, respectively, for body atrophy of any severity. The area under the receiver operating characteristic curve was 0.84 (95\% CI 0.69 to 0.99 ) for body atrophy of any severity. The median (interquartile range) of PGI:II in patients with none, mild, moderate and severe atrophy was 5.93 (3.5), 4.73 (3.9), 3.11 (3.5) and 1.85 (0.7), respectively. The non-parametric test showed that values of PGI:II in patients with moderate $(p<0.05)$ and severe $(p<0.01)$ atrophy were significantly lower than those without atrophy.

\section{Statistical analyses}

Relative risks of cancer between groups of $H$ pylori serostatus, PGI:II and gastrin concentrations were estimated as odds ratios (ORs) with associated 95\% CIs using conditional logistic regression analyses. ${ }^{24}$ By exploiting the algorithmic equivalence of proportional hazards regression and conditional logistic regression, asymptotic ORs were computed using the Cox module of the SPSS V.7.5 statistical computer software package, with each matched set as a separate stratum. For separate analyses of $H$ pylori-seropositive and $H$ pylori-seronegative cases and controls, we used unconditional logistic 
regression with adjustment for the matching variables in the original study design. Unconditional logistic regression produced estimates similar to comparable conditional regression analyses. Tests of contrasts in ORs between subgroups of subjects were performed by including an interaction term in the statistical model. For tests of linear trend, the categorised variable was treated as a continuous variable, and for tests of homogeneity, the variable was represented with indicator variables. Two-sided $p$ values $<0.05$ were considered significant.

\section{RESULTS}

We studied 131 (76\%) men and $42(24 \%)$ women with 390 and 118 matched controls, respectively. In the non-cardia subsites, there were 91 men and 38 women. In the cardia, predominance for men was much more pronounced, with 40 men vs four women. Serum was sampled between 1972 and 1986, with $98 \%$ of the samples collected between 1972 and 1977. Median age at serum sampling was 45.6 (range 23.6-63.4) years and median follow-up time to diagnosis of cancer was 11.9 (range 0.3-20.3) years in the cases. Median age at diagnosis of cardia cancer was 57.5 (range 43.6-63.3) years, and median age at diagnosis of non-cardia cancer was 55.8 (range 34.3-68.2) years. The time span over which the serum samples were obtained preceded the introduction of proton pump inhibitor medication in Norway.

As reported previously, the association between $H$ pylori seropositivity and cancer was highly dependent on the gastric subsite $^{14}$ (table 1). H pylori seropositivity was found in $90 \%$ (116/129) of the non-cardia cases and in 43\% (19/44) of the cardia cases, as compared with 66\% (247/376) and 71\% (93/132) in the respective control groups. There was a negative association between the infection and cancer of the cardia (OR $0.27,95 \%$ CI 0.12 to 0.59 ). This contrasted with the positive association in the non-cardia subsites collectively (OR 4.75, 95\% CI 2.56 to $8.81 ; \mathrm{p}<0.001)$. The OR in the antrum and pylorus combined (OR 7.95, 95\% CI 3.07 to 20.6) was non-significantly higher $(\mathrm{p}=0.09)$ than in the fundus and body combined (OR $2.67,95 \%$ CI 1.14 to 6.25 ).

\section{SERUM PGI:II}

Figure 1 shows the individual PGI:II results. In non-cardia subsites collectively, there was a strong association between PGI:II and the subsequent development of cancer. The risk of non-cardia cancer increased monotonously with decreasing quintiles of PGI:II (table 1). A PGI:II $<2.69$ (lowest quintile) conferred an overall 11.6 (95\% CI 4.91 to 27.5 ) times higher risk of non-cardia cancer than a ratio $>6.06$ (highest quintile; $p$ for trend over quintiles $<0.001)$. The associations were similar for the proximal and distal non-cardia subsites (data not shown). With PGI:II values dichotomised, PGI:II $<2.5$ was associated with a 4.47 (95\% CI 2.71 to 7.37 ) times higher risk of noncardia cancer than PGI:II $>2.5$ (table 2). A statistically significant association between low PGI:II and non-cardia cancer was found in both $H$ pylori-positive and $H$ pylori-negative subjects when analysed separately (table 2 ).

In the cardia, quintiles of PGI:II showed no linear association with risk of cancer ( $\mathrm{p}$ for trend 0.391; table 1 ). However, when PGI:II was dichotomised and $H$ pylori-seropositive cases and controls were analysed separately, an association between atrophy and cardia cancer was found. $H$ pylori-positive individuals with a PGI:II $<2.5$ had a 3.33 (CI 1.06 to 10.5 ) times higher risk of developing cardia cancer relative to subjects with PGI:II $>2.5$ (table 2). There were no $H$ pylori-negative cases or controls with PGI:II $<2.5$ precluding an analogous analysis of $H$ pylori-negative subjects.

\section{SERUM GASTRIN}

Figure 2 shows the individual serum gastrin results. In non-cardia subsites collectively, a monotonously increasing risk with increasing serum gastrin quintiles was observed, the risk being 8.99 (95\% CI 3.96 to 20.4) times higher for gastrin values $\geqslant 95 \mathrm{ng} / \mathrm{l}$ than for values $\leqslant 20 \mathrm{ng} / \mathrm{l}$ (table 1 ). The pattern was similar in proximal and distal non-cardia subsites, with ORs tending to be slightly higher in the distal subsites (data not shown). Length of time between the last meal and serum sampling was known for 120 (93\%) of the noncardia cases and 352 (95\%) of corresponding controls. In this subgroup of subjects, the association between serum gastrin concentration and cancer was estimated before and after adjustment for time since the last meal. Overall, the adjustment did not

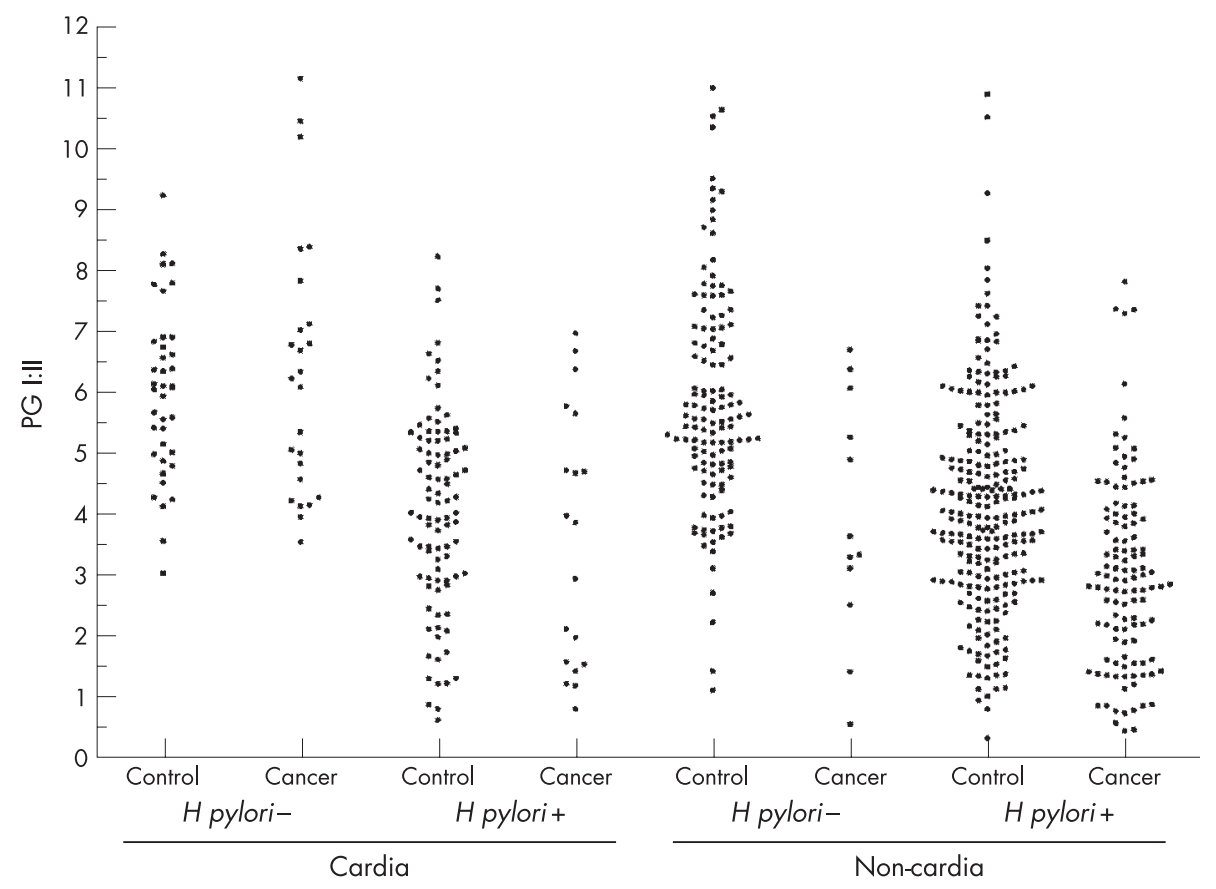

Figure 1 Serum pepsinogen I:II (PGI:II) in patients with cancer and their controls by subsite and Helicobacter pylori status. 
Table 2 Risk of adenocarcinoma for serum pepsinogen I:II $<2.5$ (relative to serum pepsinogen I:II $>2.5$ ) and serum gastrin concentration $\geqslant 60 \mathrm{ng} / \mathrm{l}$ (relative to serum gastrin concentration $<60 \mathrm{ng} / \mathrm{l}$ ) according to gastric subsites and Helicobacter pylori serostatus

\begin{tabular}{|c|c|c|c|}
\hline \multirow{2}{*}{$\begin{array}{l}\text { Gastric subsite } \\
\text { Risk factor }\end{array}$} & \multicolumn{2}{|l|}{ H pylori serostatus } & \multirow[b]{2}{*}{ Seronegative } \\
\hline & Overall & Seropositive & \\
\hline $\begin{array}{l}\text { Non-cardia } \\
\text { Pepsinogen I:II }>2.5 \\
\text { Pepsinogen I:II }<2.5 \\
\text { p Value } \\
\text { Gastrin }<60 \mathrm{ng} / / \\
\text { Gastrin } \geqslant 60 \mathrm{ng} / \mathrm{l} \\
\text { p Value }\end{array}$ & $\begin{array}{l}129 \text { cases, } 376 \text { controls } \\
1.00 \text { (reference) } \\
4.47 \text { (2.71 to } 7.37 \text { ) } \\
<0.001 \\
1.00 \text { (reference) } \\
3.18 \text { (2.03 to } 4.99 \text { ) } \\
<0.001\end{array}$ & $\begin{array}{l}116 \text { cases, } 247 \text { controls } \\
1.00 \text { (reference) } \\
3.45 \text { (2.01 to } 5.91) \\
<0.001 \\
1.00 \text { (reference) } \\
2.77 \text { (1.69 to } 4.54 \text { ) } \\
<0.001\end{array}$ & $\begin{array}{l}13 \text { cases, } 129 \text { controls } \\
1.00 \text { (reference) } \\
12.6(2.25 \text { to } 70.7)^{*} \\
0.004 \\
1.00 \text { (reference) } \\
3.05 \text { (0.71 to } 13.1 \text { ) } \\
0.133\end{array}$ \\
\hline $\begin{array}{l}\text { Cardia } \\
\text { Pepsinogen I:II }>2.5 \\
\text { Pepsinogen } 1: \| l<2.5 \\
\text { p Value } \\
\text { Gastrin }<60 \mathrm{ng} / \mathrm{I} \\
\text { Gastrin } \geqslant 60 \mathrm{ng} / \mathrm{l} \\
\text { p Value }\end{array}$ & $\begin{array}{l}44 \text { cases, } 132 \text { controls } \\
1.00 \text { (reference) } \\
1.60 \text { (0.62 to } 4.14 \text { ) } \\
0.333 \\
1.00 \text { (reference) } \\
0.88 \text { (0.37 to } 2.06 \text { ) } \\
0.761\end{array}$ & $\begin{array}{l}19 \text { cases, } 93 \text { controls } \\
1.00 \text { (reference) } \\
3.33 \text { ( } 1.06 \text { to } 10.5 \text { ) } \\
0.039 \\
1.00 \text { (reference) } \\
2.23 \text { (0.63 to } 7.87 \text { ) } \\
0.213\end{array}$ & $\begin{array}{l}25 \text { cases, } 39 \text { controls } \\
1.00 \text { (reference) } \\
t \\
1.00 \text { (reference) } \\
0.38 \text { (0.05 to } 3.03 \text { ) } \\
0.362\end{array}$ \\
\hline
\end{tabular}

Risk of adenocarcinoma estimated by $\mathrm{OR}$ with associated $95 \% \mathrm{Cl}$ in an unconditional logistic regression model with adjustment for the matching variables in the original study design.

*Unconditional logistic regression analysis without adjustment for the matching variables (only three cases with pepsinogen I:II $<2.5$ precluded adjustment)

†There were no $H$ pylori seronegative cardia cases or controls with pepsinogen l:II $<2.5$.

materially alter the point estimates for cardia or non-cardia subsites. However, the adjustment increased the ORs in the distal non-cardia subsites by approximately $30 \%$ within each of the serum gastrin concentration quintiles. In an unconditional logistic regression model with adjustment for the variables used for matching in the study design, dichotomising serum gastrin values at $\geqslant 60 \mathrm{ng} / \mathrm{l}$ was most discriminating, conferring a 3.18 (95\% CI 2.03 to 4.99 ) times increased risk of non-cardia cancer relative to gastrin concentrations $<60 \mathrm{ng} / \mathrm{l}$. This association was apparent and was of the same order of magnitude in both $H$ pylori-positive (OR 2.77, 95\% CI 1.69 to 4.54) and H pylori-negative (OR 3.05, 95\% CI 0.71 to 13.1 ) individuals analysed separately (table 2 ).

In the cardia, there was no linear association between serum gastrin concentration tertiles ( $\mathrm{p}$ for trend 1.00), quartiles ( $\mathrm{p}$ for trend 0.41 ) or quintiles ( $\mathrm{p}$ for trend 0.70 ; table 1 ) and later development of cancer, nor did gastrin dichotomised at various cut-off values show any association with cardia cancer. However, separate analyses for $H$ pylori-positive and $H$ pylori-negative cases and controls suggested associations proceeding in opposite directions. In an unconditional logistic regression model, hypergastrinaemia (cut-off at $60 \mathrm{ng} / \mathrm{l}$ ) tended to be positively associated with cardia cancer in $H$ pylori-seropositive patients (OR $2.23,95 \%$ CI 0.63 to 7.87 ) but negatively associated in $H$ pyloriseronegative patients (OR $0.38,95 \%$ CI (0.05 to 3.03); a test for homogeneity between ORs gave $p=0.093$ ). Adjustment for time since the last meal did not weaken the associations in the subset of subjects for whom this information was available.

\section{HISTOLOGICAL SUBTYPES}

The cardia and non-cardia cancers had different distributions of histological subtypes. Of the 129 non-cardia cancers, 59 (46\%) were intestinal, $35(27 \%)$ diffuse and $31(24 \%)$ mixed, and four $(3 \%)$

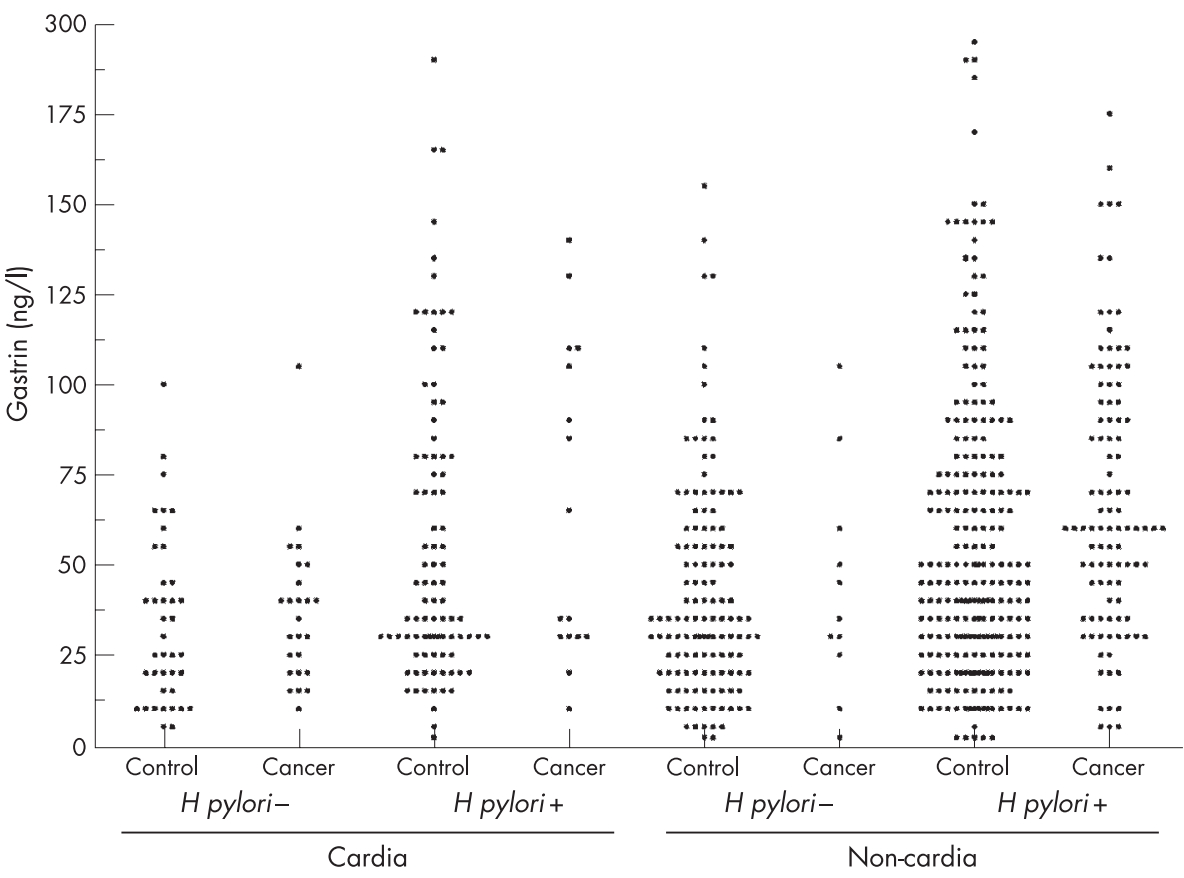

Figure 2 Serum gastrin in patients with cancer and their controls by subsite and Helicobacter pylori status. 
were of unclassifiable histological subtype. By contrast, the 44 cardia cancers comprised 31 (71\%) intestinal, seven (16\%) diffuse, five ( $11 \%$ ) mixed and one (2\%) unclassifiable histological subtypes. The proportion of intestinal to diffuse subtype was significantly higher in the cardia versus non-cardia subsite $(\mathrm{p}<0.05)$

In the non-cardia region, the risk of each of the three histological subtypes increased similarly with decreasing quintiles of PGI:II and increasing quintiles of serum gastrin (table 1).

In the cardia, however, the different adenocarcinoma subtypes showed different associations with both PGI:II and gastrin. For these analyses, the variables were dichotomised because of the limited number of cardia cancers and controls. And for comparison, analogous analyses based on dichotomised variables were performed for the non-cardia subsites (table 3). PGI:II <2.5 (relative to PGI:II >2.5) was associated with an increased risk of the diffuse subtype at both non-cardia (OR $3.21,95 \%$ CI 1.27 to 8.13 ) and cardia subsites (OR 3.46, 0.32 to 37.5). Similarly, there was a tendency towards an association between serum gastrin $\geqslant 60 \mathrm{ng} / \mathrm{l}$ (relative to serum gastrin $<60 \mathrm{ng} / \mathrm{l}$ ) and the diffuse subtype in both the non-cardia (OR $2.11,95 \%$ CI 0.92 to 4.86 ) and the cardia subsites (OR 5.30, 95\% CI 0.52 to 54.6). With respect to the intestinal subtype, both low PGI:II and high serum gastrin showed disparate effects between the two subsites. Low PGI:II was positively associated with the intestinal subtype at non-cardia sites (OR 6.68, 95\% CI 2.79 to 16.0), but apparently not at the cardia sites (OR 0.72, $95 \%$ CI 0.19 to 2.79 ; table 3 ). The contrast in ORs was highly significant $(p=0.007)$. Likewise, hypergastrinaemia was positively associated with the intestinal subtype in non-cardia subsites (OR 4.04, 95\% CI 2.05 to 7.96 ), but not at the cardia subsites (OR $0.59,95 \%$ CI 0.22 to 1.58; table 3 ). This difference in ORs was also highly significant $(\mathrm{p}=0.002)$.

The eight cardia cancers that occurred in patients with atrophic (PGI:II <2.5) stomachs were all $H$ pylori positive (fig 2 ). Three of these cancers were of intestinal, three were of diffuse and two were of mixed histological subtype, and this distribution of histological subtypes was similar to that of the $H$ pyloripositive non-cardia cancers. The 36 cardia cancers that occurred in patients with non-atrophic (PGI:II >2.5) stomachs were predominantly $H$ pylori negative $(69 \%)$ and had a distribution of histological subtypes that was different from the non-cardia cancers, the intestinal subtype being more prevalent in the cardia $(78 \%)$ cancers than in the non-cardia $(46 \%)$ cancers.

\section{DISCUSSION}

This study shows the association between the premorbid state of the gastric mucosa and the location and histological subtypes of gastric adenocarcinoma presenting over subsequent years. Cancers of the mid and distal stomach of all histological subtypes were positively associated with $H$ pylori infection, atrophy and hypochlorhydria. Cardia cancer was more complex; it was negatively associated with $H$ pylori infection and the predominant intestinal subtype of cardia cancer was not associated with gastric atrophy. However, in patients with $H$ pylori infection, cardia cancer was positively associated with atrophy and hypochlorhydria. These findings can be explained by cardia cancer being of two distinct aetiologies, some cases being similar to non-cardia cancer and others having a different aetiology.

The findings with non-cardia cancer are consistent with current knowledge that its development is a multistage process. $^{7}$ H pylori infection induces superficial gastritis, which progresses to atrophic gastritis with loss of acid secretion and then to dysplasia and cancer. Various bacterial, host and environmental factors are known to contribute to the progress through these different pre-cancerous stages. ${ }^{25}$

The multistage process of non-cardia cancer development has been traditionally more strongly associated with the development of the intestinal histological subtype of cancer, as the diffuse type may develop in subjects with normal gastric mucosa. ${ }^{26}$ In the latter cases, there is often a strong hereditary predisposition with inherited germline mutations. ${ }^{27}$ Our current study, however, along with that of Uemura et al, ${ }^{6}$ indicates that atrophy and hypochlorhydria are associated with increased risk of the diffuse and mixed histological subtypes, as well as with intestinal gastric cancer.

The association between atrophy and non-cardia cancer was apparent in both the $H$ pylori-seropositive and $H$ pylori-seronegative patients, the association being statistically non-significantly stronger in the $H$ pylori-seronegative subjects. $H$ pylori seronegativity in some of these individuals may be explained by atrophy and hypochlorhydria causing loss of $H$ pylori infection and seropositivity. ${ }^{28-30}$ Previous studies have shown that patients with evidence of atrophy and no evidence of $H$ pylori have the highest risk for cancer. ${ }^{30}$ Some of the non-cardia cancers may have arisen from gastric atrophy due to causes other than $H$ pylori-for example, autoimmune atrophic gastritis.

In addition to using PGI:II as a marker of atrophy, we also used serum gastrin as a marker of atrophy and hypochlorhydria.

Table 3 Risk of adenocarcinoma for serum pepsinogen I:II $<2.5$ (relative to serum pepsinogen I:II $>2.5$ ) and serum gastrin concentration $\geqslant 60 \mathrm{ng} /$ ( relative to serum gastrin concentration $<60 \mathrm{ng} /$ l) according to gastric subsites and adenocarcinoma subtypes

\begin{tabular}{|c|c|c|c|c|}
\hline \multirow{2}{*}{$\begin{array}{l}\text { Gastric subsite } \\
\text { risk factor }\end{array}$} & \multicolumn{2}{|l|}{ Histology } & \multirow[b]{2}{*}{ Diffuse } & \multirow[b]{2}{*}{ Mixed } \\
\hline & Overall* & Intestinal & & \\
\hline Non-cardia & 129 cases, 376 controls & 59 cases, 173 controls & 35 cases, 100 controls & 31 cases, 91 controls \\
\hline Pepsinogen I:II > 2.5 & 1.00 (reference) & 1.00 (reference) & 1.00 (reference) & 1.00 (reference) \\
\hline Pepsinogen I:II $<2.5$ & $4.32(2.58$ to 7.24$)$ & $6.68(2.79$ to 16.0$)$ & 3.21 (1.27 to 8.13$)$ & $2.32(0.86$ to 6.25$)$ \\
\hline $\mathrm{p}$ Value & $<0.001$ & $<0.001$ & 0.014 & 0.097 \\
\hline Gastrin < 60 ng/l & 1.00 (reference) & 1.00 (reference) & 1.00 (reference) & 1.00 (reference) \\
\hline Gastrin $\geqslant 60 \mathrm{ng} / \mathrm{l}$ & $2.97(1.92$ to 4.61$)$ & 4.04 (2.05 to 7.96$)$ & $2.11(0.92$ to 4.86$)$ & 2.40 (1.06 to 5.44$)$ \\
\hline $\mathrm{p}$ Value & $<0.001$ & $<0.001$ & 0.079 & 0.036 \\
\hline Cardia & 44 cases, 132 controls & 31 cases, 93 controls & 7 cases, 21 controls & 5 cases, 15 controls \\
\hline Pepsinogen I:II > 2.5 & 1.00 (reference) & 1.00 (reference) & 1.00 (reference) & 1.00 (reference) \\
\hline Pepsinogen I:II $<2.5$ & $1.56(0.60$ to 4.09$)$ & $0.72(0.19$ to 2.79$)$ & $3.46(0.32$ to 37.5$)$ & - \\
\hline $\mathrm{p}$ Value & 0.365 & 0.632 & 0.307 & \\
\hline Gastrin < 60 ng/l & 1.00 (reference) & 1.00 (reference) & 1.00 (reference) & 1.00 (reference) \\
\hline Gastrin $\geqslant 60$ ng/l & 0.85 (0.38 to 1.88$)$ & $0.59(0.22$ to 1.58$)$ & $5.30(0.52$ to 54.6$)$ & 0.69 (0.06 to 8.04$)$ \\
\hline p Value & 0.689 & 0.295 & 0.161 & 0.764 \\
\hline
\end{tabular}

Risk of adenocarcinoma estimated by OR with associated $95 \% \mathrm{Cl}$.

*Including four histologically unclassifiable cases and 12 corresponding controls. - not applicable. 


\begin{tabular}{|c|c|c|c|c|c|c|c|c|c|c|c|c|}
\hline \multirow{2}{*}{$\begin{array}{l}\text { Gastric subsite } \\
\text { Gastric mucosa }\end{array}$} & \multicolumn{12}{|c|}{$\begin{array}{c}\text { Cardia } \\
44\end{array}$} \\
\hline & \multicolumn{6}{|c|}{$\begin{array}{c}\text { Atrophic } \\
8\end{array}$} & \multicolumn{6}{|c|}{$\begin{array}{c}\text { Non-Atrophic } \\
36\end{array}$} \\
\hline $\begin{array}{l}H \text { pylori } \\
\text { serostatus }\end{array}$ & \multicolumn{3}{|c|}{$\begin{array}{c}\text { Positive } \\
8\end{array}$} & \multicolumn{3}{|c|}{$\begin{array}{c}\text { Negative } \\
0\end{array}$} & \multicolumn{3}{|c|}{$\begin{array}{c}\text { Positive } \\
11\end{array}$} & \multicolumn{3}{|c|}{$\begin{array}{c}\text { Negative } \\
25\end{array}$} \\
\hline $\begin{array}{l}\text { Adenocarcinoma } \\
\text { subtype }\end{array}$ & $\begin{array}{c}\text { Intestinal } \\
3\end{array}$ & $\begin{array}{c}\text { Mixed } \\
2\end{array}$ & $\begin{array}{c}\text { Diffuse } \\
\quad 3\end{array}$ & $\begin{array}{c}\text { Intestinal } \\
0\end{array}$ & $\begin{array}{c}\text { Mixed } \\
0\end{array}$ & $\begin{array}{c}\text { Diffuse } \\
0\end{array}$ & $\begin{array}{c}\text { Diffuse } \\
2\end{array}$ & $\begin{array}{c}\text { Mixed } \\
2\end{array}$ & $\begin{array}{c}\text { Intestinal } \\
7\end{array}$ & $\begin{array}{c}\text { Diffuse } \\
2\end{array}$ & $\begin{array}{c}\text { Mixed } \\
2\end{array}$ & $\begin{array}{c}\text { Intestinal } \\
21\end{array}$ \\
\hline
\end{tabular}

Atrophic gastritis notably impairs the ability of the stomach to secrete acid, which stimulates a rise in the circulating concentration of the hormone gastrin. Serum gastrin has been shown to be an independent predictor of atrophic gastritis in subgroups with and without $H$ pylori infection. ${ }^{31}$ Similar to PGI:II, serum gastrin is most sensitive to atrophic gastritis affecting the gastric body where the acid-secreting parietal cells are located. ${ }^{32}$ Serum gastrin increases linearly with an increase in grade of atrophy of the body mucosa and exponentially with a decrease in peak acid output from normal ( $>10 \mathrm{meq} / \mathrm{h}$ ) to zero. ${ }^{33}$ In patients with achlorhydria or severe hypochlorhydria (peak acid output $<1.1 \mathrm{meq} / \mathrm{h}$ ), the degree of accompanying hypergastrinaemia decreases linearly with increasing grade of antral atrophy. ${ }^{33}$ This moderating influence of antral atrophy is thought to be due to loss of antral $\mathrm{G}$ cells, and thus inability to produce the high rate of gastrin secretion stimulated by profound hypochlorhydria. ${ }^{33}$

There was a particularly strong association between increase in serum gastrin level and subsequent risk of non-cardia cancer. It is possible that the rise in serum gastrin level associated with atrophy and low acidity may promote the carcinogenic process. ${ }^{34}$ The hypergastrinaemic mouse model develops invasive gastric cancer, an effect that is markedly accelerated by $H$ pylori infection and inhibited by gastrin receptor antagonism. ${ }^{35-37}$

The state and function of the gastric mucosa associated with cardia cancer is more complex than that associated with non-cardia cancer. In contrast with non-cardia cancer, there was a negative association between $H$ pylori infection and cardia cancer. As $H$ pylori infection causes atrophy and hypochlorhydria, we expected to find a lower prevalence of atrophy and hypochlorhydria in patients with cardia cancers than in controls because of the lower prevalence of $H$ pylori in patients with cardia cancer (table 1). Such a finding would be consistent with $H$ pylori protecting from cardia cancer by the same mechanism by which it predisposes to non-cardia cancerthat is, by reducing gastric acidity. However, despite the significantly lower prevalence of $H$ pylori infection in patients with cardia cancer ( $43 \%$ vs $71 \%$ in controls), the prevalence of atrophy was at least as high in the cases ( $18 \%)$ as in the controls ( $13 \%)$. The reason for this unexpected finding was that the prevalence of atrophy in the $H$ pylori-positive patients with cardia cancer was significantly higher than the $H$ pylori-positive controls. Patients with cardia cancer were thus characterised by having a significantly lower prevalence of $H$ pylori infection but higher prevalence of atrophy in those with the infection than in the controls.

What is the explanation for the complex association between the premorbid state of the gastric mucosa and cardia cancer? The lower prevalence of $H$ pylori infection is consistent with $H$ pylori having some protective effect. However, the high prevalence of atrophic gastritis in the $H$ pylori-infected subjects suggests that atrophic gastritis due to $H$ pylori predisposes to cardia cancer. The most plausible explanation for our findings is that cancer of the cardia region has a heterogeneous aetiology and arises by two different pathways, with $H$ pylori exerting an opposite influence on the two pathways.

The positive association with atrophic gastritis in the $H$ pyloriinfected patients with cardia cancer is consistent with a subgroup of cardia cancers having an aetiology similar to non-cardia cancer-that is, due to $H$ pylori infection progressing to atrophic gastritis and cancer. The serological markers of atrophy detect atrophy mostly involving the body mucosa. ${ }^{32} 3839$ Body atrophy induced by $H$ pylori gastritis causes distal regression of the apparent cardia-oxyntic junction because of loss of specialised cells. ${ }^{13}$ Our finding is consistent with a proportion of the cardia cancers having arisen from this process and thus being of an aetiology similar to non-cardia cancer. Ye $e t a l^{40}$ recently reported that cardia cancer was not associated with $H$ pylori infection but with gastric atrophy, and their observation is also thus consistent with atrophy being involved in a subgroup of cardia cancers.

The lower prevalence of $H$ pylori infection in patients with cardia cancer supports an additional aetiological pathway in which $H$ pylori may exert a protective influence. Several studies have reported a negative association between $H$ pylori infection and oesophageal adenocarcinoma. ${ }^{40}{ }^{41}$ A subgroup of the cardia cancers may have an aetiology similar to oesophageal adenocarcinoma and be subject to a $H$ pylori protective influence. Proximal expansion of the cardia mucosa can arise by metaplasia of oesophageal mucosa, which is the same process that is thought to lead to oesophageal adenocarcinoma and to be induced by reflux of gastric acid. ${ }^{9-12}$ The mechanism by which $H$ pylori infection may protect from this process is unclear, but it may be because it causes a fall in acid output with advancing years owing to the development of atrophy. ${ }^{42} 43$

The analyses of the histological subtypes provide further evidence of two distinct aetiologies of cardia cancer. Atrophy tended to increase the risk of the diffuse subtype of cardia cancer to an extent similar to which it increased the diffuse subtype of noncardia cancer. This was apparent by using either PGI:II or gastrin as the marker of atrophy. However, our data suggested that atrophy does not increase the risk of intestinal-type cardia cancer, which was in contrast with the increased risk of intestinal-type cancer in the non-cardia region. The contrast in associations between atrophy and intestinal-type cancer in the cardia versus non-cardia regions was highly significant when using either low PGI:II $(p=0.007)$ or high gastrin $(p=0.002)$ as risk indicators. The diffuse-type cancers at the cardia thus seems to be aetiologically similar to diffuse non-cardia cancers, whereas the intestinal-type cancers at the cardia (or at least most of them) are aetiologically distinct from intestinal-type cancers in the non-cardia region.

The cardia cancers that occurred in patients with atrophic gastritis (all of whom were $H$ pylori positive) had similar proportions of intestinal and diffuse histological subtypes as in 
the non-cardia cancers. This is consistent with them being of an aetiology similar to non-cardia cancer arising from $H$ pyloriinduced atrophic gastritis (fig 2). However, the cardia cancers occurring in patients with non-atrophic stomachs $(69 \%$ of which were $H$ pylori seronegative) had a much higher proportion of intestinal versus diffuse histological subtype $(7: 1)$. This predominant intestinal histological subtype is similar to that reported in oesophageal adenocarcinoma ${ }^{44}$ and is consistent with this subgroup being of an aetiology similar to oesophageal adenocarcinoma.

Our observations are relevant to the hypothesis that $H$ pylori infection may protect from oesophageal adenocarcinoma as well as predispose to gastric cancer and that both effects are mediated by gastric atrophy. To demonstrate a possible protective effect of $H$ pylori infection on oesophageal adenocarcinoma via gastric atrophy, it will be essential to study only oesophageal adenocarcinomas well clear of the gastro-oesophageal junction. Inclusion of any cardia cancers will obscure a possible protective effect of atrophy due to the subgroup of cardia cancers associated with gastric atrophy.

Our finding may also be relevant to the conflicting reports on the association between $H$ pylori infection and cardia cancer. ${ }^{145}$ In general, the association has tended to be negative in studies originating from the West and positive in studies from the East. $^{145}$ Our observation of some cardia cancers aetiologically resembling oesophageal adenocarcinoma and others resembling non-cardia adenocarcinoma may explain the conflicting associations of cardia cancer with $H$ pylori. In parts of the world where oesophageal adenocarcinoma is relatively common, most cardia cancers are aetiologically similar to oesophageal adenocarcinoma and a protective effect of $H$ pylori infection and associated atrophy is apparent. By contrast, in parts of the world such as the East where oesophageal adenocarcinoma is rare and non-cardia gastric cancer is common, the predominant aetiological type of cardia cancer will resemble non-cardia cancer and show a positive association with $H$ pylori and atrophic gastritis.

One practical implication of our findings is that the state of the gastric mucosa may provide a key to determining the origin of cardia cancer. As already discussed, it is usually impossible to determine the origin of such cancers by examining them grossly or microscopically. However, if examination of the stomach well clear of the cancerous process reveals atrophic gastritis, then cardia cancer of the intestinal histological subtype is likely to be aetiologically similar to non-cardia cancer and to have arisen from original gastric mucosa. By contrast, if the patient has a healthy non-atrophic gastric mucosa, then cardia cancer of the intestinal histological subtype is likely to be of an aetiology similar to oesophageal adenocarcinoma and to have arisen from metaplastic oesophageal mucosa produced by gastroesophageal reflux. We have recently proposed that cardia cancers of the intestinal histological subtype arising in patients with evidence of gastric atrophy should be termed type A and those arising in patients without gastric atrophy termed type $\mathrm{B} \cdot{ }^{46}$ Cardia cancers of the diffuse histological subtype are likely to be gastric in origin.

In conclusion, our studies indicate that cardia cancers probably comprise two distinct aetiological subtypes, one resembling non-cardia gastric cancer and positively associated with $H$ pylori atrophic gastritis and the other resembling oesophageal adenocarcinoma and negatively associated with $H$ pylori atrophic gastritis. Further studies with larger numbers of cancers are required to determine whether the state of the gastric mucosa will indeed provide the key to differentiate between gastric versus oesophageal origin of cardia cancers.

\footnotetext{
Authors' affiliations

Svein Hansen, The Cancer Registry of Norway, Institute of Populationbased Cancer Research, Oslo, Norway
}

Stein Emil Vollset, Section for Epidemiology and Medical Statistics, Department of Public Health and Primary Health Care, University of Bergen, Bergen, Norway

Mohammad H Derakhshan, Valerie Fyfe, Kenneth E L McColl, Division of Medical Sciences, Western Infirmary, University of Glasgow, Glasgow, UK Kjetil K Melby, Department of Microbiology, Ullevaal University Hospital, Oslo, Norway

Steinar Aase, Department of Pathology, Haukeland University Hospital, University of Bergen, Bergen, Norway

Egil Jellum, Institute of Clinical Biochemistry, Rikshospitalet, University of Oslo, Oslo, Norway

Competing interests: None.

\section{REFERENCES}

1 Helicobacter and Cancer Collaborative Group. Gastric cancer and Helicobacter pylori: a combined analysis of 12 case control studies nested within prospective cohorts. Gut 2001;49:347-53.

2 Hansson LE, Sparén $P, N y r e ́ n ~ O$. Increasing incidence of carcinoma of the gastric cardia in Sweden from 1970 to 1985. Br J Surg 1993;80:374-7.

3 Blot WJ, Devesa SS, Kneller RW, et al. Rising incidence of adenocarcinoma of the esophagus and gastric cardia. JAMA 1991;265:1287-9.

4 Antonioli DA, Goldman H. Changes in the location and type of gastric adenocarcinoma. Cancer 1982;50:775-81.

5 Hansen S, Wiig JN, Giercksky KE, et al. Esophageal and gastric carcinoma in Norway 1958-1992: incidence time trend variability according to morphological subtypes and organ subsites. Int J Cancer 1997;71:340-4.

6 Uemura N, Okamoto S, Yamamoto S, et al. Helicobacter pylori infection and the development of gastric cancer. N Engl J Med 2001;345:784-9.

7 Correa P. Human gastric carcinogenesis: a multistep and multifactorial processfirst American Cancer Society Award lecture on cancer epidemiology and prevention. Cancer Res 1992;52:6735-40.

8 Glickman JN, Fox V, Antonioli DA, et al. Morphology of the cardia and significance of carditis in pediatric patients. Am J Surg Pathol 2002;26:1032-9.

9 Wolf C, Seldenrijk CA, Timmer R, et al. Does carditis have two different etiologies? Dig Dis Sci 2001;46:2424-32.

10 Chandrasoma PT, Der R, Ma Y, et al. Histology of the gastresophageal junction: an autopsy study. Am J Surg Pathol 2000;24:402-9.

11 Spechler SJ. Intestinal metaplasia at the gastroesophageal junction. Gastroenterology 2004;126:567-75.

12 Odze RD. Unraveling the mystery of the gastroesophageal junction: a pathologist's perspective. Am J Gastroenterol 2005;100:1853-67.

13 Van Zanten SJ, Dixon MF, Lee A. The gastric transitional zones: neglected links between gastroduodenal pathology and helicobacter ecology. Gastroenterology 1999;116:1217-29.

14 Hansen S, Melby KK, Aase S, et al. Helicobacter pylori infection and risk of cardia cancer and non-cardia gastric cancer. A nested case-control study. Scand J Gastroenterol 1999;34:353-60.

15 Jellum $E$, Andersen A, Lund-Larsen $P$, et al. Experiences of the Janus Serum Bank in Norway. Environ Health Perspect 1995;103(Suppl 3):85-8.

16 Bjartveit K, Foss OP, Gjervig T, et al. The cardiovascular disease study in Norwegian counties. Background and organization. Acta Med Scand Suppl 1979;634:1-70.

17 Bjartveit K, Foss OP, Gjervig T. The cardiovascular disease study in Norwegian counties: results from first screening. Acta Med Scand Suppl 1983:675:1-184.

18 Hiermann I, Velve Byre K, Holme I, et al. Effect of diet and smoking intervention on the incidence of coronary heart disease. Report from the Oslo Study Group of a randomized trial in healthy men. Lancet 1981;2:1303-10.

19 World Health Organization. International classification of diseases for oncology, 2nd edn. Geneva: WHO, 1990.

20 Laurén $\mathbf{P}$. The two histological main types of gastric carcinoma: diffuse and socalled intestinal-type carcinoma. An attempt at a histo-clinical classification. Acto Pathol Microbiol Scand 1965:64:31-49.

21 Pilotti S, Rilke F, Clemente C, et al. The cytologic diagnosis of gastric carcinoma related to the histologic type. Acta Cytol 1977;21:48-59.

22 Mulholland G, Ardill JES, Fillmore D, et al. Helicobacter pylori related hypergastrinaemia is the result of a selective increase in gastrin 17. Gut 1993:34:757-61.

23 Dixon MF, Genta RM, Yardley JH, et al. Classification and grading of gastritis. The updated Sydney System. International workshop on the Histopathology of Gastritis, Houston, 1994. Am J Surg Pathol 1996;20:1161-81.

24 Hosmer DW, Lemeshow S. Applied logistic regression. New York: John Wiley \& Sons, 1989

25 McColl KEL, El-Omar E. How does $\mathrm{H}$. pylori infection cause gastric cancer? Keio J Med 2002;51(Suppl 2):53-6.

26 Siurala M, Varis K, Sipponen P. Carcinogenesis in the foregut: gastric carcinoma. In: Baron JH, Moody FG, eds. Foregut. London: Butterworths International Medical, 1981.

27 Fitzgerald RC, Caldas C. Clinical implications of E-cadherin associated hereditary diffuse gastric cancer. Gut 2004:53:775-8.

28 Fukuda H, Saito D, Hayashi S, et al. Helicobacter pylori infection, serum pepsinogen level and gastric cancer: a case-control study in Japan. Jpn J Cancer Res 1995;86:64-71

29 Tabata H, Fuchigami T, Kobayashi H, et al. Helicobacter pylori and mucosal atrophy in patients with gastric cancer: a special study regarding the methods for detecting Helicobacter pylori. Dig Dis Sci 1999;44:2027-34. 
30 Watabe $\mathrm{H}$, Mitsushima T, Yamaii Y, et al. Predicting the development of gastric cancer from combining Helicobacter pylori antibodies and serum pepsinogen status: a prospective endoscopic cohort study. Gut 2005;54:764-8.

31 Katelaris PH, Seow F, Lin CPC, et al. Effect of age, Helicobacter pylori infection and gastritis with atrophy on serum gastrin and gastric acid secretion in healthy men. Gut 1993;34:1032-7.

32 Sipponen $\mathrm{P}$, Ranta $\mathrm{P}$, Helske T, et al. Serum levels of amidated gastrin-17 and pepsinogen I in atrophic gastritis: an observational case-control study. Scand J Gastroenterol 2002;37:785-91.

33 Sipponen $\mathbf{P}$, Valle J, Varis $\mathrm{K}$, et al. Fasting levels of serum gastrin in different functional and morphologic states of the antrofundal mucosa. Scand I Gastroneterol 1990;25:513-19.

34 Aly A, Shulkes A, Baldwin GS. Gastrins, cholecystokinins and gastrointestinal cancer. Biochim Biophys Acta 2004;1704:1-10.

35 Takaishi S, Cui G, Frederick DM, et al. Synergistic inhibitory effects of gastrin and histamine receptor antagonists on Helicobacter-induced gastric cancer. Gastroenterology 2005;128:1965-83

36 Fox JG, Rogers $A B$, Ihrig $M$, et al. Helicobacter pylori-associated gastric cancer in INS-GAS mice is gender specific. Cancer Res 2003:63:942-50.

37 Wang TC, Dangler CA, Chen D, et al. Synergistic interaction between hypergastrinemia and Helicobacter infection in a mouse model of gastric cancer. Gastroenterology 2000;1 18:36-47.

38 Vaananen $\mathrm{H}$, Vauhkonen M, Helske T, et al. Non-endoscopic diagnosis of atrophic gastritis with a blood test. Correlation between gastric histology and serum levels of gastrin-17 and pepsinogen I: a multicentre study, Eur J Gastroenterol Hepatol 2003;15:885-91.

39 Knight T, Wyatt J, Wilson A, et al. Helicobacter pylori gastritis and serum pepsinogen levels in a healthy population: development of a biomarker strategy for gastric atrophy in high risk groups. Br J Cancer 1996;73:819-24.

$40 \mathrm{Ye} \mathrm{W}$, Held M, Lagergren J, et al. Helicobacter pylori infection and gastric atrophy: risk of adenocarcinoma and squamous-cell carcinoma of the esophagus and adenocarcinoma of the gastric cardia. J Natl Cancer Inst 2004;96:388-96.

41 Henrik Siman J, Forsgren A, Berglund G, et al. Helicobacter pylori infection is associated with a decreased risk of developing esophageal neoplasms. Helicobacter 2001;6:310-16.

42 Bahmanyar S, Zendehdel K, Nyren O, et al. Risk of oesophageal cancer by histology among patients hospitalised for gastroduodenal ulcers. Gut 2007;56:464-8.

43 McColl KEL. Commentary. Helicobacter pylori and oesophageal cancer-not always protective. Gut 2007; 56:457-9.

44 Reid BJ. Barrett's esophagus and esophageal adenocarcinoma. Gastroenterol Clin North Am 1991;20:817-34.

45 Kamangar F, Dawsey SM, Blaser MJ, et al. Opposing risks of gastric cardia and noncardia gastric adenocarcinomas associated with Helicobacter pylori seropositivity. J Natl Cancer Inst 2006;98:1445-52.

$46 \mathrm{McColl} \mathrm{KEL}$. Cancer of the gastric cardia. Best Pract Res Clin Gastroenterol 2006;20:687-96 